\title{
"I'M AN IMMIGRANT": COSMOPOLITISMO, ALTERIDADE E FLUXOS COMUNICACIONAIS EM UMA CAMPANHA ANTI-XENOFOBIA NO REINO UNIDO
}

Denise Cogo ${ }^{1}$

Viviane Riege ${ }^{2}$

\begin{abstract}
Este artigo tem como objetivo refletir sobre as relações entre comunicação, cosmopolitismo e alteridade nos processos migratórios, a partir da análise crítica do discurso de uma campanha publicitária anti-xenofobia, denominada "I'm an Immigrant", realizada em 2015 no Reino Unido. A partir de uma discussão conceitual acerca das noções de cosmopolitismo, identidades e alteridade nas suas conexões com as representações e práticas de cidadania das migrações transnacionais, analisamos os discursos dos textos das peças da campanha que foram veiculadas em espaços urbanos da cidade de Londres e em espaços digitais da internet. A análise evidenciou que a campanha colabora para atribuir visibilidade aos migrantes a partir da singularização de suas trajetórias. Contudo, essa singularização se constrói, por um lado, a partir da ênfase em uma dimensão economicista que associa imigração a trabalho, sem expor suas contradições, e, por outro lado, é fundamentada em um modelo ocidental, branco e laico que opera para o apagamento de diferenças que constituem as culturas migratórias do Reino Unido.
\end{abstract}

Palavras-chave: migrações transnacionais, cosmopolitismo, alteridade, fluxos comunicacionais, Reino Unido.

\section{Introdução}

Cosmopolitismo é uma palavra de origem grega, kosmopolítes, sendo que kosmós significa 'mundo' e polites 'cidadão'. O conceito de cosmopolitismo tem sido fruto de reflexões no campo da filosofia há séculos e mais recentemente no campo das ciências sociais, principalmente pelas discussões propostas

1 Professora Titular do Programa de Pós-Graduação em Comunicação e Práticas de Consumo da ESPM-SP. Pesquisadora do CNPq. São Paulo, SP, Brasil.

2 Doutoranda em Comunicação e Práticas de Consumo pela Escola Superior de Propaganda e Marketing (ESPM-SP). Bolsista CAPES/Prosup. São Paulo, SP, Brasil. 
por Ülf Hannerz ${ }^{3}$, Ulrich Beck ${ }^{4}$ e Gerard Delanty ${ }^{5}$. Os estudos recentes sobre cosmopolitismo surgem no campo de estudos sobre os fenômenos da globalização. Nas referências ocidentais europeias, o cosmopolita é delineado como um sujeito altamente móvel, curioso, aberto e reflexivo, que se deleita com e deseja consumir a diferença, especialmente por ocasião de mobilidades internacionais, experiências em outros países ou outras formas de relações sociais transnacionais ${ }^{6}$.

Uma vez que há múltiplas visões possíveis e dimensões diversas para a discussão desse conceito, falamos em cosmopolitismos, devido à sua pluralidade tanto teórica quanto analítica. Da mesma forma, devido aos diferentes contextos e experiências dos sujeitos ao redor do mundo, em relação às suas práticas de comunicação e cidadania, propomos os seguintes questionamentos: será que o cosmopolitismo é um ideal ou uma característica que pode ser atribuída a todos? Ou seria essa uma qualidade somente acessível para alguns sujeitos participantes da sociedade contemporânea global?

Para refletirmos sobre o cosmopolitismo nos processos migratórios, propomos, neste artigo, uma análise dos fluxos comunicacionais sobre migrações no contexto britânico, materializado em uma campanha publicitária que circulou recentemente no Reino Unido. O país recebeu imigrantes em diferentes etapas históricas que contribuíram para a composição étnico-cultural diversa de suas populações e para a constituição de espaços de vivências cosmopolitas, mas também para a produção de diferentes práticas xenófobas que têm a imigração como alvo.

A história do Reino Unido é caracterizada pela recepção de povos, como celtas, romanos, anglos, saxões, francos, dinamarqueses e noruegueses (vikings), e também normandos, povos europeus que habitaram, invadiram e/ou permaneceram no território britânico durante a Idade Antiga e o início da Idade Média. Durante a idade média, houve a chegada de judeus (principalmente poloneses), o que voltou a ocorrer no final do século XIX e no período anterior à 2a Guerra Mundial. $\mathrm{O}$ censo demográfico oficial britânico ${ }^{7}$, realizado desde 1851, mostra que até 1931 o número de pessoas nascidas no exterior vivendo no Reino Unido era pouco expressivo no total da população. Depois de 1945, um grande número de indianos e de europeus (alemães, italianos, austríacos) também começou a buscar o Reino Unido como país de destino, seja pela situação de vitória do país aliado, seja pelas oportunidades de emprego presentes nesse período - que incluíam emissão de vistos de trabalho pelo governo britânico. Como consequência do período de colonização, o British Nationality Act de 1948 concedeu aos indivíduos nascidos nos países que eram parte do império

3 HANNERZ, UIf. Cosmopolitans and locals in world culture.

4 BECK, Ulrich. Qu'est-ce que le cosmopolitisme?

5 DELANTY, Gerard. The cosmopolitan imagination: critical cosmopolitanism and social theory.

6 URRY, John. Consuming Places.

7 Realizado pelo Office for National Statistics, ONS, disponível em: < http://www.ons.gov.uk>. 
britânico (Austrália, Nova Zelândia, Canadá, Quênia e África do Sul) o direito de morar e trabalhar no Reino Unido. O fluxo de crescimento de imigrantes parou logo em seguida, em 1951, e ficou estagnado até final dos anos 1990. Após esse período, o número de imigrantes no país voltou a crescer, principalmente pela possibilidade de circulação de europeus, devido à abertura das fronteiras internas da União Europeia e à chegada de indivíduos do continente africano e do Caribe, principalmente pedindo asilo, como refugiados ${ }^{8}$.

No contexto contemporâneo britânico, tem se produzido debates públicos e polêmicos em torno da questão da imigração, os quais têm mobilizado, de modo especial, os meios de comunicação. O programa de competição culinária da BBC, o "The Great British Bake Off", uma das produções de maior audiência no país em 2015, teve como vencedora uma descendente muçulmana de imigrantes de Bangladesh, fato que causou discussões xenófobas nas redes sociais e na mídia conservadora ${ }^{9}$. Na transmissão da Copa do Mundo de Rugby, houve repercussão das diferenças entre a Rugby Union (que possui como principais seleções a Austrália, a Nova Zelândia e a África do Sul) e a Rugby League (baseada no norte da Inglaterra) ${ }^{10}$ por meio de críticas e de atos de repúdio em relação a jogadores de diferentes nacionalidades que se sobressaiam nas diferentes seleções.

Em sua atuação política e humanitária no âmbito das migrações, o Reino Unido recebeu, ainda, críticas recentes das Nações Unidas, dentre as quais a acusação de prática de xenofobia em relação aos imigrantes que buscavam refúgio na região de Calais (na passagem para o território britânico) ${ }^{11}$. Essa demanda de entrada por imigrantes no país também recebeu diversas críticas por parte da opinião pública britânica, principalmente no período próximo às eleições parlamentares - incluindo a declaração polêmica da colunista Katie Hopkins, comparando os imigrantes a baratas ${ }^{12}-$, o que contribuiu para reforçar uma atuação do governo orientada ao fechamento das fronteiras.

No contexto dessas práticas de xenofobia frente à imigração, a análise aqui proposta orienta-se à reflexão sobre o desenvolvimento no Reino Unido de uma campanha de comunicação anti-xenofobia, denominada "I'm an Immigrant", em 2015. A campanha foi produzida pela organização não governamental britânica (ONG) No Xenophobia ${ }^{13}$, e veiculada em espaços urbanos, como estações de

8 Uma síntese da trajetória da imigração do Reino Unido está disponível em: <http://www. migrationwatchuk.org/briefing-paper/6.1>.

9 Ver reportagem em: <http://www.spectator.co.uk/2015/10/what-the-great-british-bake-off-reallysays-about-britain/>.

${ }^{10}$ Ver reportagem em: <http://www.nytimes.com/2015/10/16/world/europe/immigration-backdropto-rugby-and-great-british-bake-off.html?_r=0>.

${ }^{11}$ Ver reportagem em: <http://www.express.co.uk/news/uk/595112/Peter-Sutherland-UnitedNations-Britain-Calais-migrant-crisis-Eurotunnel-France $>$.

${ }^{12} \mathrm{Ver}$ reportagem em: <http://www.independent.co.uk/news/uk/politics/katie-hopkins-migrantcockroaches-column-resembles-pro-genocide-propaganda-says-the-un-10201959.html > .

${ }^{13}$ Cf. <http://www.noxenophobia.org>. 
metrô e pontos de ônibus, focando principalmente na capital, Londres, assim como em espaços digitais, com o objetivo de dar visibilidade a trajetórias de imigrantes que contribuíram para a sociedade local. A proposta da campanha foi mostrar a identidade dos imigrantes que vivem no país, para destacar o seu pertencimento à sociedade local, ou, ainda, "celebrá-los", termo utilizado na assinatura do material de comunicação da ONG produtora da campanha: "Immigrants are part of the fabric of our society. It's time to celebrate, not vilify".

Realizamos esta análise visando compreender os tipos de representação sobre os imigrantes construídos por essa campanha e sua relação com as noções de identidade e alteridade constitutivas das experiências de cosmopolitismo que envolvem as migrações transnacionais. Ao entendermos que os textos publicitários que constituem os fluxos comunicacionais contemporâneos constroem diferentes representações das migrações, buscamos analisar como esses textos são propostos para consumo. Embora não seja o objetivo deste artigo o estudo do consumo e da recepção, mas a produção dos discursos da campanha institucional, não desconsideramos as diferentes ressignificações que são possíveis a partir da circulação e da apropriação desses discursos sobre as migrações por parte de diferentes setores sociais, assim como seus impactos na própria disputa política pela constituição de verdades e/ou consensos em torno da própria ideia de imigração.

A abordagem metodológica proposta baseia-se na análise crítica do discurso de Fairclough ${ }^{14}$ e nos estudos críticos do discurso de Van Dijk ${ }^{15}$, na medida em que ambossefundamentam na proposição de queas mudanças na cultura correspondem a mudanças nas práticas do discurso. Por essa abordagem, compreendemos que textos, práticas discursivas e sociais se interligam e interinfluenciam, uma vez que "os textos simultaneamente representam a realidade, ordenam as relações sociais e estabelecem identidades"16. Pela perspectiva de Van Djik ${ }^{17}$, pensamos, ainda, os discursos como interações situadas e práticas sociais ancoradas em situações sócio-históricas, culturais e políticas específicas.

Propomos, inicialmente, um debate em torno do conceito de cosmopolitismo, suas conexões com as representações e as práticas de cidadania das migrações. Desenvolvemos, então, na segunda parte, uma reflexão acerca da identidade cosmopolita e da alteridade frente ao Outro - imigrante. A partir dessas discussões, analisamos, na terceira parte, textos de três modalidades de peças integrantes da campanha "I'm an Immigrant" - posters inseridos nos espaços urbanos, posters disponíveis no website da ONG e posts criados por indivíduos que compartilharam a campanha na rede social Twitter.

\footnotetext{
${ }^{14}$ FAIRCLOUGH, Norman. Discurso e mudança social.

${ }^{15}$ VAN DIJK, Teun A. (comp.). El discurso como interacción social.

${ }^{16}$ FAIRCLOUGH, op. cit., p. 27.

17 VAN DIJK, op. cit.
} 


\section{Cosmopolitismo: questão de estética ou ética?}

O conceito de cosmopolitismo vinculado ao de experiência estética tem como base os trabalhos de Skrbis e Woodward ${ }^{18}$, que defendem a necessidade de se continuar a olhar para as manifestações e as possibilidades de cosmopolitismo nos encontros comuns na vida cotidiana das pessoas, e de Cicchelli e Octobre ${ }^{19}$, que afirmam que há necessidade de se empregar o conceito de cosmopolitismo em relação a situações comuns e banais, como o consumo cultural cotidiano. A natureza da relação entre cosmopolitismo e estética não estaria fundada em um conhecimento organizado, mas, inicialmente, em um acúmulo de momentos resultantes desses encontros e experiências cotidianas, às vezes tanto efêmeras quanto parciais e organizadas como representações. A ligação com a alteridade seria, em primeira instância, portanto, estética ${ }^{20}$ : como, no Facebook, a pessoa "curte" (ou não), comenta (ou não), compartilha (ou não), desde o último vídeo musical lançado pela Beyoncé, até o impacto dos assassinatos realizados na sede do semanário parisiense Charlie Hebdo.

Essa relação do cosmopolitismo é, muitas vezes, reduzida às indústrias culturais/de entretenimento globais e a suas sugestões consumistas. Como no caso do turismo e lazer, onde a familiaridade com as culturas do mundo é vista como "superficial ou cosmética"21. A dimensão estética e cultural do cosmopolitismo seria acusada inclusive de manter o Outro como uma relação exótica, de reduzir a conexão com a alteridade ao consumo de bens e produtos em cenários urbanos padronizados (em situações de ansiedade de consumo pela efemeridade). A maioria das pessoas é capaz de desenvolver um cosmopolitismo estético, negando a ideia de uma única definição para o cosmopolitismo. O cosmopolitismo estético é analisado em sua morfologia individual e social: individual em sua mobilização, ele é construído nas dobras singulares do social por socializações e experiências, emoções compartilhadas e imaginários, e pode ser definido como uma disposição cultural envolvendo uma postura estética e intelectual de abertura para povos, lugares e experiências de diferentes culturas, especialmente aqueles de diferentes nações, ou de um gosto para as margens mais amplas da experiência cultural $^{22}$. Nessa perspectiva, a estética contemporânea torna-se cosmopolita: pelo reconhecimento, por parte do indivíduo, da diferença entre os seus códigos estéticos vernaculares e aqueles dos produtos culturais estrangeiros consumidos; pela comparação dos códigos sem uma hierarquização necessária em uma escala

\footnotetext{
${ }^{18}$ SKRBIS, Zlatko, WOODWARD, Ian. Cosmopolitanism: uses of the idea.

${ }^{19} \mathrm{CICCHELLI}$, Vincenzo, OCTOBRE, Sylvie. A cosmopolitan perspective of globalization: cultural and aesthetic consumption among young people.

${ }^{20}$ IDEM. Sur le cosmopolitisme esthétique chez les jeunes.

${ }^{21}$ SASSATELLI, Monica. Festivals, museums, exhibitions: aesthetic cosmopolitanism in the cultural public sphere, p. 235.

22 CICCHELLI, Vincenzo, OCTOBRE, Sylvie, RIEGEL, Viviane. Reflections on global culture and aesthetic cosmopolitanism.
} 
de valor; pelo desenvolvimento de competências na manipulação desses códigos estéticos através de um processo de familiarização; e pelo desenvolvimento de uma intencionalidade para a descoberta da cultura do produto.

No marco dessa lógica da estética cosmopolita, os fluxos comunicacionais produzem e reproduzem as imagens de quem seriam os cidadãos do mundo. A publicidade, que se converteu em uma manifestação comunicativa integrada na cultura e nos valores sociais, constrói a própria cultura cotidiana, dando visibilidade para determinados grupos e estilos de vida, e apagando outros. No caso dos imigrantes, frequentemente há um apagamento das diversas barreiras com as quais se deparam para a entrada e inserção nas sociedades para onde migram, uma vez que, conforme aponta Sandro Mezzadra ${ }^{23}$, as fronteiras não estão abertas da mesma forma e a inclusão social ocorre de maneira diferenciada para esses indivíduos, que são privados de diversos direitos de cidadãos.

Assim, há a necessidade também de uma discussão ética acerca do cosmopolitismo, que vá além do consumo e da lógica do mercado, e que permita a compreensão das práticas de cidadania de diferentes sujeitos. Na visão de uma ética para o consumo de Adela Cortina ${ }^{24}$, há aqueles que não possuem acesso a bens entre os quais podem escolher (ou a formas de produzi-los), e também os que poderiam exercer seu direito de escolha, mas o delegam a grupos ou instituições de referência, aos meios de comunicação ou ao marketing. Essa discussão acerca de uma ética cosmopolita exige, ainda, o reconhecimento da cidadania universal como uma dimensão de cidadania que se pauta em princípios de reconhecimento e defesa da livre circulação e vigência dos direitos sociais dos imigrantes para além de seu pertencimento a um país de nascimento ou origem ${ }^{25}$. No caso dos grupos de imigrantes, as barreiras físicas e simbólicas são difíceis de se transpor, uma vez que as apropriações e reelaborações culturais, assim como o sentimento de pertencimento, são construções individuais e coletivas que estão condicionadas pela ausência ou limitação de acesso dos imigrantes a diversos direitos sociais (educação, saúde, moradia, idioma, etc.).

\section{Identidade, representações e alteridade - questões cosmopolitas sobre as migrações}

Stuart Hall ${ }^{26}$, estudioso das identidades e da diáspora, aborda as dinâmicas contemporâneas de descentralização das identidades para evidenciar o deslocamento da noção de identidade como uma experiência permanente, fixa e autêntica, que vai dar a lugar à sua compreensão como um processo fragmentado e híbrido relacionado a pertencimentos como os de classe, raça,

\footnotetext{
${ }^{23}$ MEZZADRA, Sandro. Derecho de fuga: migraciones, ciudadanía y globalización.

${ }^{24}$ CORTINA, Adela. Por una ética del consumo: la ciudadanía del consumidor en un mundo global.

25 IDEM. Ética sem moral.

${ }^{26}$ HALL, Stuart. Cultural Identity and Diaspora.
} 
gênero e nação, e das dimensões local, nacional e global. Nesse processo, a questão central que interessa à análise aqui proposta diz respeito ao caráter relacional das identidades. É na relação com o Outro que as identidades se inscrevem na ordem dos discursos, se (re)constroem através de representações que se produzem em narrativas sobre quem somos em relação a esse Outro ${ }^{27}$. O conceito de representação faz referência, na visão do autor, ao emprego da linguagem para construir e oferecer sentidos sobre o mundo. Por meio das representações, os sujeitos produzem interações entre si, conformam e disputam sentidos sobre o mundo. A materialização dessas representações está permeada simbolicamente por relações de poder, no marco das quais se produzem "regimes de representação" sobre as culturas e as identidades, que resultam de processos de dominação, mas também negociação, entre sujeitos sociais.

Frente à realidade dos fluxos de migrações no mundo e das diásporas, as identidades se constituem a partir de uma variedade de discursos ancorados na noção de diferença, especialmente aqueles relacionados à etnicidade ${ }^{28}$. O autor retoma os pensamentos nacionalistas e racistas para explicá-los como estruturas de discurso e de representação que, a partir do foco nas identidades étnicas, buscam expulsar esse Outro, seja simbolicamente, por sua marginalização, seja fisicamente, através da construção de fronteiras e barreiras de acesso a direitos. Como exemplos de estruturas discursivas que produzem a diferença como exclusão, estão os estereótipos que mostram a relação entre representação, diferença e poder (físico e simbólico), e são um elemento chave para as práticas de violência simbólica.

Zygmunt Bauman ${ }^{29}$ também aponta para o ressurgimento da etnia como uma forma de lealdade de grupos minoritários e marginalizados que demarcam os processos de constituição das identidades na pós-modernidade. O que poderia produzir, na visão do autor, uma clara divisão entre o pertencimento a um determinado grupo étnico culturalmente semelhante e o pertencimento a um grupo de cidadãos com plenos direitos. A questão do pertencimento torna-se, portanto, relevante para a discussão sobre as identidades e a cidadania dos imigrantes na medida em que se fundamenta nas necessidades e demandas de grupos culturalmente diversos e de origens nacionais distintas. Nessa perspectiva, uma das principais repercussões dos atuais processos migratórios tem sido justamente a de contestar os contornos estabelecidos das chamadas identidades nacionais e de expor seu fechamento às pressões da diferença, da alteridade e da diversidade cultural, fazendo com que "toda a questão da identidade nacional e da 'centralidade' do Ocidente fosse abertamente discutida" ${ }^{30}$.

\footnotetext{
${ }^{27}$ Ibidem.

${ }^{28}$ Ibidem.

${ }^{29}$ BAUMAN, Zygmunt. Modernity and Ambivalence.

${ }^{30}$ HALL, op. cit., p. 90.
} 
Ao tratar do conceito de alteridade, Abdelmalek Sayad ${ }^{31}$ ressalta que a presença de estrangeiros no espaço nacional é normalmente considerada como provisória, mesmo que a realidade desminta essa representação. A ruptura com esse pensamento resulta em argumentos utilizados em muitas ações xenofóbicas, contrárias à alteridade, como uma maneira de justificar que o estrangeiro não pertence àquele lugar, que causa problemas para a sociedade local e que deve, portanto, ser fisicamente expulso - além da expulsão simbólica que ocorre nas práticas cotidianas em relação a esses sujeitos. Nesse aspecto, muitos dos questionamentos feitos pelos nacionais em relação à presença e condição dos imigrantes remetem à dimensão econômica. A ocupação dos postos de trabalho destinados aos nacionais, assim como a sobrecarga que representariam os imigrantes em termos de moradia ${ }^{32}$ e acesso a serviços sociais e públicos, como saúde e educação, são argumentos que têm sustentado frequentemente a construção de uma alteridade fundada na premissa da "imigração como problema".

Para a análise sobre a imigração nos países receptores, o autor ${ }^{33}$ propõe um deslocamento do foco na questão da identidade (seja da identidade imigrante como definidora do sujeito, seja da identidade cultural fixa que somente se refere ao país de origem). Para ele, o imigrante está em uma situação permanente de confronto entre duas realidades, a de seu país de origem - presente em seu imaginário e no pensamento constante de um possível retorno -, e a de um país no qual ele colocou suas ilusões, seus projetos de vida, e no qual ele busca sobreviver. A partir dessa relação, a diferença torna-se um elemento indissociável nas experiências dos imigrantes, indispensável para a sua inserção no contexto social contemporâneo, impondo a necessidade de um debate sobre a alteridade como valor ético.

A partir dessa breve reflexão sobre identidade, representações e alteridade, torna-se relevante problematizar a questão cosmopolita especificamente relacionada à imigração. Como propõe Norbert Bilbeny ${ }^{34}$, o cosmopolitismo pode ser explicado tanto como multiculturalismo (para uma visão liberal), como estética (para uma visão de esquerda), como uma banalização da globalização (para uma visão crítica) ou como uma utopia (para os internacionalistas). Para o autor, a identidade cosmopolita estaria conectada à moral, diferenciando-se da moral nacionalista, uma vez que prioriza a humanidade à nação. Nesse confronto entre $\mathrm{o}$ nacional e o cosmopolita, situa-se a questão da segurança e dos direitos adquiridos para o nacional, e o da liberdade e da cidadania universal para os "não nacionais", os imigrantes. Diante dos fluxos de globalização e da consequente interdependência das dimensões econômica, política, cultural nas sociedades contemporâneas, o

\footnotetext{
${ }^{31}$ SAYAD, Abdelmalek. L'immigration ou les paradoxes de l'altérité.

${ }^{32}$ Exemplo da visão sobre crise de moradia e a presença de imigrantes no Reino Unido na discussão do artigo: <http://www.theguardian.com/housing-network/2016/jan/25/is-immigration-causingthe-uk-housing-crisis $>$.

33 SAYAD, op. cit.

${ }^{34}$ BILBENY, Norbert. La identidad cosmopolita.
} 
cosmopolitismo surge como um princípio ideológico, mas também como uma postura diante do Outro, que pode orientar as práticas relacionadas às questões de identidade e alteridade das migrações transnacionais.

\section{Análise da campanha "I am an Immigrant" da ONG No Xenophobia}

A fim de compreender como se constroem, no campo comunicacional, as relações entre cosmopolitismo e alteridade das migrações, passamos a analisar os posters e posts da campanha intitulada "I am an Immigrant", da ONG No Xenophobia ${ }^{35}$. Baseada na proposta de Fairclough ${ }^{36}$, a análise está orientada por três dimensões observadas nos textos da campanha: a) problema social e aspectos do discurso; b) elementos discursivos do problema social (atores sociais, espacialidades e práticas sociais); e c) reflexão crítica da análise do discurso sobre o problema social.

Os posters intitulados "I am an Immigrant", da ONG No Xenophobia, foram colocados em pontos de grande circulação da cidade de Londres (pontos de ônibus, mais de 400 estações de metrô), em estações de trem no país todo, e disponibilizados em versão digital, para compartilhamento em redes sociais (como Facebook e Twitter) em 2015. O objetivo das peças produzidas é dar visibilidade ao Movimento Contra a Xenofobia (Movement Against Xenophobia) no Reino Unido, apresentando sujeitos imigrantes, dando-lhes rosto e identidade, e mostrando suas contribuições para a sociedade.

A campanha foi pensada com vistas a propor um diálogo com as políticas migratórias que promovem a discriminação dos imigrantes no país ${ }^{37}$, principalmente diante de discussões midiáticas e políticas que constroem posicionamentos que se opõem à entrada de estrangeiros no Reino Unido ${ }^{38}$. Apesar da imigração não ser um elemento novo na sociedade britânica, ela se tornou mais presente nas preocupações da opinião pública recentemente, tanto com o crescimento de grupos migrantes na última década, quanto pela possibilidade da entrada de refugiados sírios (considerada como uma crise na Europa e no país ${ }^{39}$ ). Uma pesquisa realizada pelo Observatory of Migration da University of Oxford $^{40}$ em 2015 mostra que aproximadamente 3/4 da população britânica são a favor de reduzir o número de imigrantes no país. A xenofobia presente na opinião pública no país tem sido reproduzida por diversos atores

\footnotetext{
35 Todas as figuras de imagens da campanha apresentadas nesse artigo foram extraídas do website e da conta da rede social Twitter da ONG No Xenophobia.

${ }^{36}$ FAIRCLOUGH, op. cit.

37 O resumo das mudanças nas regras de imigração no Reino Unidos em 2015 está disponível no link: $<$ https://www.gov.uk/government/news/immigration-rules-changes $>$.

${ }^{38}$ Especialmente aquelas que se desenrolaram por ocasião das eleições parlamentares de 2015.

${ }^{39}$ Exemplo de matéria jornalística sobre a crise dos refugiados sírios no Reino Unido: <http://www. bbc.com/news/uk-35111321>.

${ }^{40}$ Relatório da pesquisa disponível em: <http://www.migrationobservatory.ox.ac.uk/sites/files/ migobs/Public\%20Opinion-Overall\%20Attitudes\%20and\%20Level\%20of\%20Concern.pdf>.
} 
sociais, como partidos políticos e por meios de comunicação de posicionamento conservador, que concentram suas críticas à imigração, considerando-a causa de diversos problemas no Reino Unido, principalmente os econômicos, relacionados à competitividade de mercado de trabalho e gastos públicos com população migrante. O governo britânico também tem se mostrado desfavorável à questão da imigração ${ }^{41}$ através da edição de medidas que estabelecem diversas barreiras para a entrada ${ }^{42}$ e permanência ${ }^{43}$ de imigrantes no país.

Posicionando-se contra essa perspectiva xenófoba, a ONG Movement Against Xenophobia (Figura 1), uma organização formada por uma rede de organizações, grupos e indivíduos que trabalham contra a agenda anti-imigração no Reino Unido ${ }^{44}$, lançou a campanha "I am an Immigrant".

\section{Figura 1 - Imagem do Movement Against Xenophobia do site e da página do Facebook}

\section{MOVEMENT AGAINST XENOPHOBIA STOP BLAMING IMMIGRANTS}

Fonte: <www.noxenophobia.org>. Acesso em: 16.01.2016.

As espacialidades utilizadas para a publicização da campanha foram tanto contextos urbanos, como ruas, estações de metrô e de trem, quanto os contextos digitais, como website e os sites de redes sociais Facebook e Twitter.

Os espaços urbanos permitem a visibilidade do discurso contra a xenofobia nas práticas cotidianas dos indivíduos nas cidades. A inserção dos rostos dos imigrantes nos posters afixados em pontos de ônibus e estações de metrô permite que esses indivíduos ganhem visibilidade pública em uma perspectiva de contraposição aos discursos xenofóbicos. Apresentamos dois posters da campanha em espaços urbanos nas Figuras 2 e 3.

\footnotetext{
${ }^{41}$ Conforme lei de imigração aprovada no $2^{\mathrm{o}}$ semestre de 2015: < https://www.gov.uk/government/ collections/immigration-bill-2015-16>.

${ }^{42}$ Ver reportagem em: <http://www.breitbart.com/london/2015/11/26/uk-immigration-hits-record-high/> .

${ }^{43}$ Ver reportagem em: < http://neurope.eu/article/uk-non-eu-migrants-earn-less-than-35000-wouldbe-deported/>.

${ }^{44}$ Ver lista de membros em: <http://www.noxenophobia.org/about/who-are-we/>.
} 


\section{Figura 2 - Poster da campanha "I am an Immigrant" em rua de Londres}

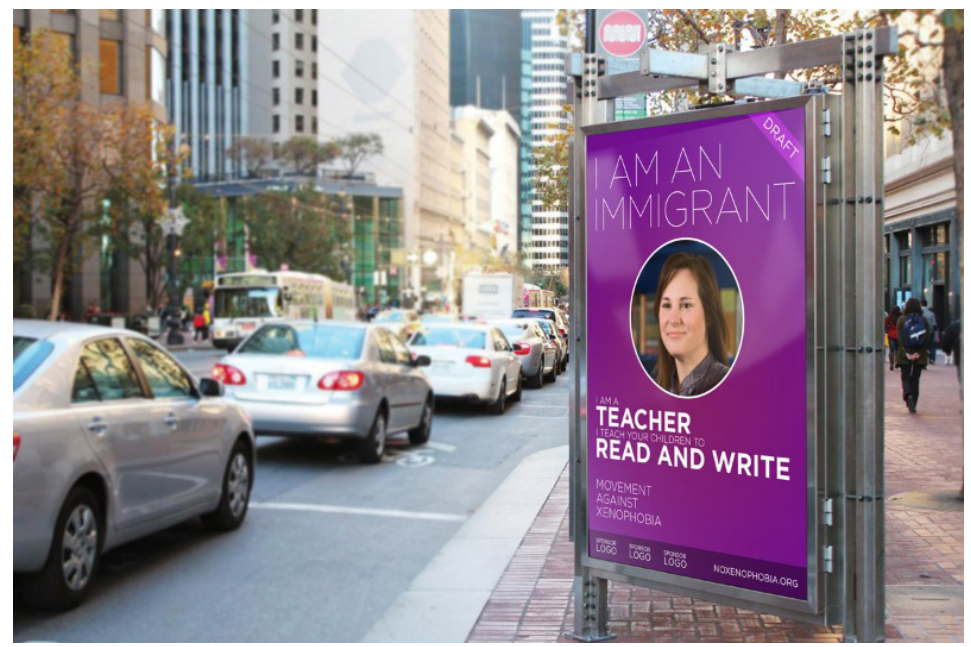

Fonte: <www.crowdfunder.co.uk/i-am-an-immigrant-poster-campaign >. Acesso em: 14.07.2015.

\section{Figura 3 - Poster da campanha "I am an Immigrant" em estação de metrô} em Londres

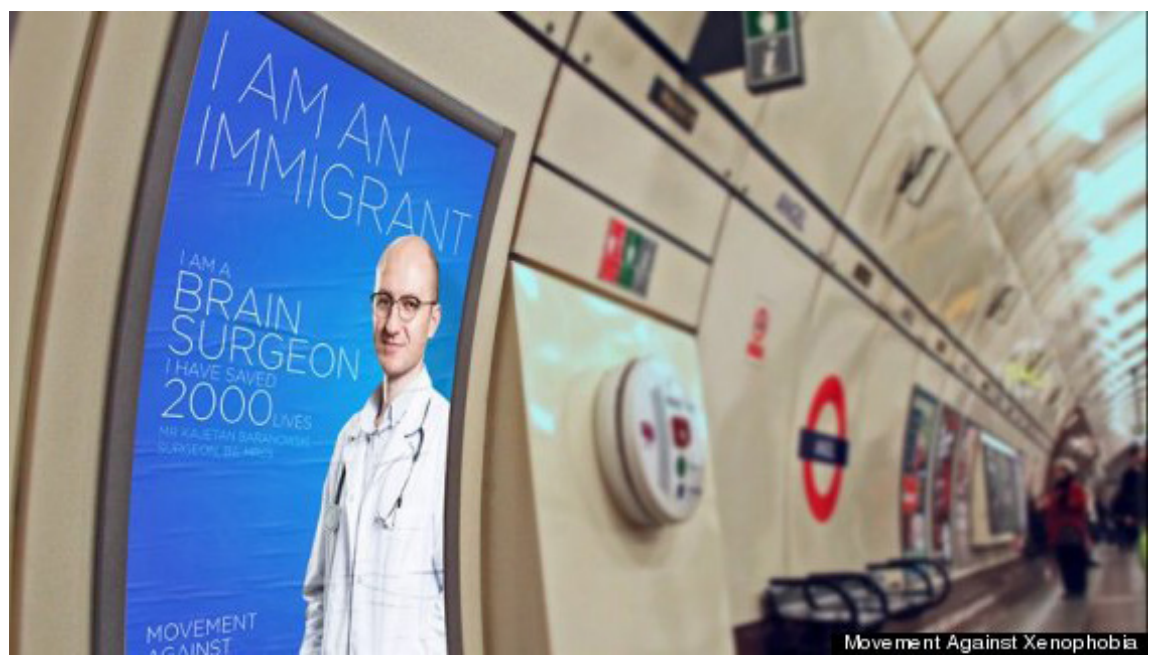

Fonte: <www.crowdfunder.co.uk/i-am-an-immigrant-poster-campaign>. Acesso em: 14.07.2015.

No poster da Figura 2 é apresentada uma imigrante que é professora, que ensina crianças a ler e escrever. Esse texto busca deslocar o estereótipo de falta de formação (imigrantes seriam classificados como desqualificados) e de falta de contribuição para a sociedade (como alguém que trabalha e produz resultados a partir desse trabalho). No poster da Figura 3 é apresentado um imigrante 
que atua como cirurgião neurológico e que salvou 2000 vidas. Seu nome está escrito no texto, oferecendo assim a identificação desse imigrante, que não busca se esconder e manter-se anônimo ou "ilegal". Ao optar pela identificação e personalização de imigrantes nas fotos e nos textos, a partir da materialização da imagem de pessoas que vivem a experiência da imigração, há um esforço de "normalização" dessas experiências e da presença dos sujeitos migrantes no cotidiano. A utilização da primeira pessoa do singular (I am) sugere capacidade de agência desses sujeitos, uma vez que as instituições mediadoras, como as próprias ONGs, tendem a falar pelos imigrantes na defesa de seus direitos.

Os espaços digitais da campanha permitem a reprodução de discursos contra a xenofobia em páginas institucionais (como o site e a página do Facebook da ONG), e também em páginas pessoais de indivíduos que apoiam a campanha e seu conteúdo. Na versão digital, foram disponibilizados 15 posters, cada um contando a história de um imigrante, os quais poderiam ser também salvos pelos usuários para compartilhamento em redes sociais, e para impressão e divulgação em locais de interesse. Apresentamos oito posters da campanha na versão digital na Figura 4.

\section{Figura 4 - Posters da campanha "I am an Immigrant" na versão digital}

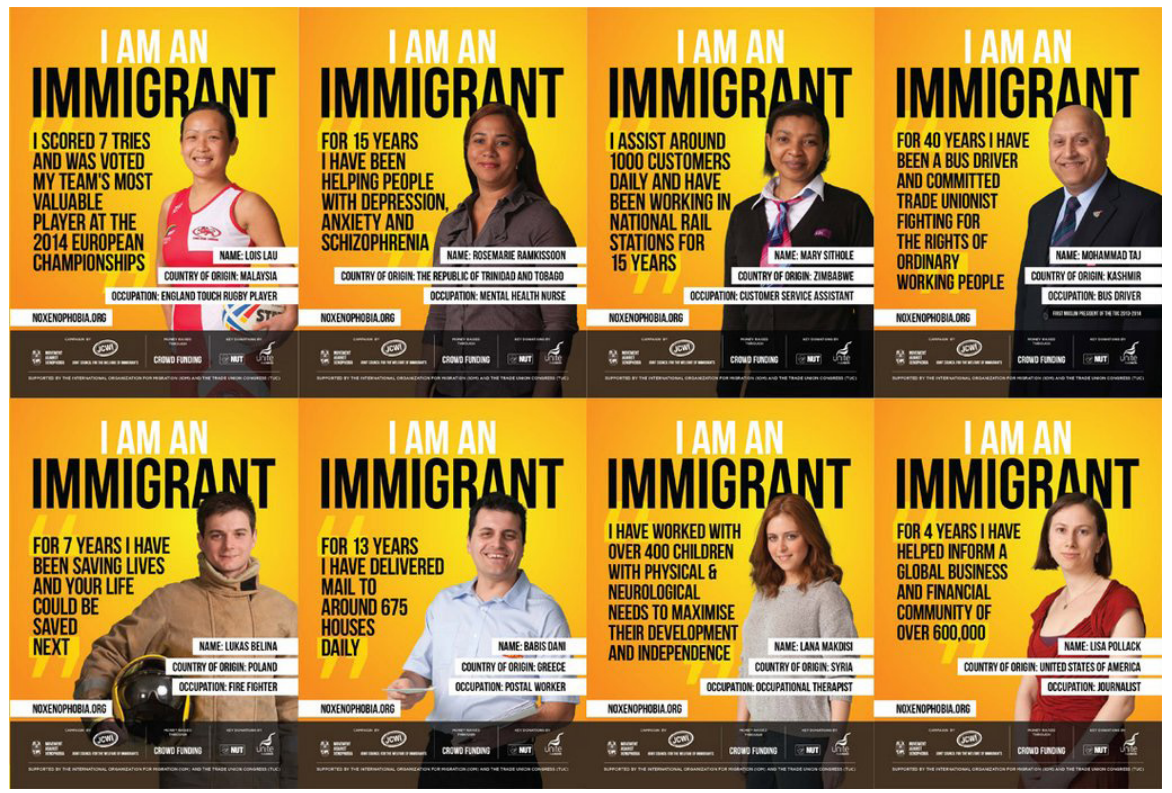

Fonte: <www.crowdfunder.co.uk/i-am-an-immigrant-poster-campaign>. Acesso em: 14.07.2015.

Esses posters seguem a proposta daqueles inseridos nos espaços urbanos, apresentando um imigrante, com seu nome, seu país de origem e sua ocupação. Além da foto, que dá rosto a esses sujeitos imigrantes, também há a inserção de uma fala de cada um. A composição da identificação dos imigrantes, em 
termos de visibilidade e o espaço de fala, sugere o esforço dos idealizadores da campanha em humanizar e tornar familiares pessoas que, em muitos casos, são tratadas como estatísticas ou de modo despersonalizado pela mídia e outras instituições. $\mathrm{O}$ ato ou sentimento de aversão aos imigrantes pode ser combatido, segundo a proposta, uma vez que se busca produzir conhecimento e empatia em relação à figura humana que se está criticando. No entanto, apesar dessa personalização e da variedade de nacionalidades dos imigrantes focalizados na campanha, uma questão que se destaca dessas representações das pessoas imigradas é a predominância de um certo padrão estético homogêneo ancorado principalmente em um modelo ocidental, branco e laico, com pouca evidência de rostos negros ou etnicamente diferenciados, ou ainda a ausência de elementos (roupas, adereços, etc.) relacionados a práticas culturais ou religiosas diversas.

Os usuários do site da ONG também tinham a possibilidade de criar seus próprios posters e reproduzi-los em suas redes sociais. Para a campanha, foi criada a hashtag \#iamanimmigrant, para identificação do compartilhamento desses materiais. Apresentamos quatro posters criados por usuários e postados na rede social Twitter nas Figuras 5, 6, 7 e 8.

Da mesma forma que os posters produzidos pela ONG, esses criados pelos usuários têm seu nome, país de origem e ocupação, incluindo também a cidade onde moram no Reino Unido, além de uma foto acompanhada de um depoimento. A possibilidade de produção dos posters pelos próprios usuários aponta para a intencionalidade da campanha em fortalecer os princípios de singularização e humanização dos imigrantes, assim como a participação e mobilização de outros imigrantes (que não os focalizados nos posters distribuídos pela cidade) visando a uma maior repercussão da própria campanha no espaço público e ampliação do debate sobre a discriminação dos imigrantes.

Figura 5 - Post do Twitter com a hashtag \#iamanimmigrant (produzido por Eddie Lepante)

MAX: Move Agnst Xeno @NoXenophobia.19 de ago de 2015

\#IAmAnlmmigrant Share your story with us iamanimmigrant.net@IOM_UK 2 IOM UK

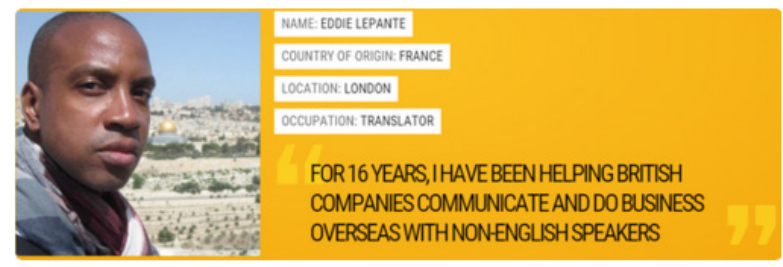

Fonte: <https://twitter.com/noxenophobia>. Acesso em: 16.01.2016. 
No post da Figura 5 o jovem de origem francesa, que trabalha como tradutor em Londres, diz que mora há 16 anos no país, e que 'ajuda empresas britânicas a se comunicarem e fazerem negócios com pessoas que não falam inglês'. Além de enfatizar sua participação como um colaborador da sociedade britânica do ponto de vista econômico e institucional - dimensão desejável de um certo ponto de vista da globalização -, ele também enfatiza um aspecto relevante na realidade cultural britânica: o fato do aprendizado e o uso de outros idiomas não serem prioridades, uma vez que o inglês é um idioma considerado internacional e globalmente utilizado.

\section{Figura 6 - Post do Twitter com a hashtag \#iamanimmigrant (produzido por Jan Rosenow)}
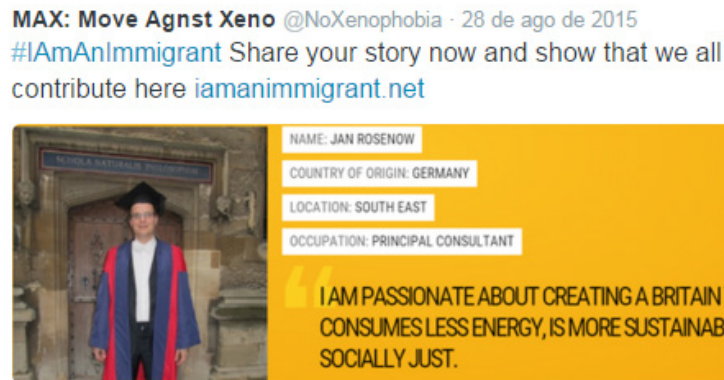

NAME: JAN ROSENOW

COUNTRY OF ORIGIN: GERMANY

LOCATION- SOUTH EAST

OCCUPATION: PRINCIPAL CONSULTANT

IAMPASSIONATEABOUT CREATINGABRITAINTHAT CONSUMESLESSENERGY,ISMORESUSTAINABLE,AND SOCIALIY JUST.

Fonte: <https://twitter.com/noxenophobia>. Acesso em: 16.01.2016.

No post da Figura 6 o homem de origem alemã, que vive na região de South East, é consultor, diz ser 'apaixonado por criar uma Bretanha que consuma menos energia (...) e seja socialmente justa'. O texto do quadro postado pelo imigrante sugere uma relação emocional com o seu campo de atuação profissional, dimensão que parece diluir aspectos mais racionais que dizem respeito a possíveis dificuldades enfrentadas na adaptação cultural ao ambiente de trabalho. Além disso, o texto remete também a ações inovadoras dos imigrantes em instâncias ambientais e também de justiça social. No entanto, ao falar em justiça social, o sujeito não aborda sua situação como imigrante, mas uma visão geral da sociedade à qual ele sente que pertence.

O post da Figura 7 mostra uma jovem portuguesa, que trabalha em Londres como assistente social, e que afirma que 'trabalha com crianças e suas famílias no serviço público por mais de 10 anos (e) leva à construção de uma comunidade mais justa'. A jovem enfatiza o tempo de trabalho no serviço social, destacando seu valor para a sociedade local, e remetendo, a exemplo do anterior, à questão de justiça social, com uma perspectiva mais direta, tendo em vista seu contato com o trabalho comunitário. Ela não destaca, no entanto, a questão dos imigrantes nessa relação de justiça social. 


\section{Figura 7 - Post do Twitter com a hashtag \#iamanimmigrant (produzido por Luisa Dornelas)}

MAX: Move Agnst Xeno @NoXenophobia - 2 de set de 2015

\#|AmAnlmmigrant Share your story Embrace your contributions to the \#UK \#immigrants contribute

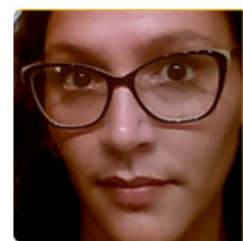

MAME LUISA DORNELAS

COUNTRY OF OBIGIN: PORTUGAL.

LOCATION: LONDON

OCCUPATION. SOCLAL WORKER

WORKINGWTTHCHILRENANDTHERFAMILESIN

PUBUICSERVICEFOROVER 10YEARS. LEADING IN

MAKINGMYOWNCOMMUNITYFAIRER

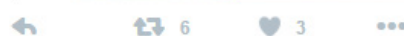

Fonte: <https://twitter.com/noxenophobia> Acesso em: 16 .01.2016.

Figura 8 - Post do Twitter com a hashtag \#iamanimmigrant (produzido por Consuelo Moreno Yusti)

MAX: Move Agnst Xeno @NoXenophobia -4 de set de 2015

\#IAmAnlmmigrant Migrants bring a lot to the \#UK society Share your story iamanimmigrant.net

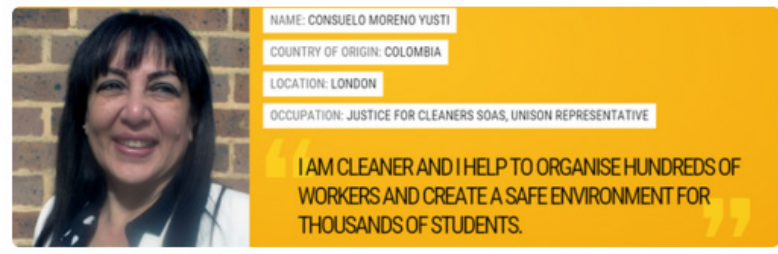

h 178 个 18 ○

Fonte: <https://twitter.com/noxenophobia >. Acesso em: 16.01.2016.

O post da Figura 8 mostra uma mulher colombiana, um exemplo de migrante latina dentre os europeus, que trabalha como representante do sindicato do serviço público em Londres. Ela se apresenta como 'uma profissional de limpeza (...) que ajuda a organizar centenas de trabalhadores e a criar um ambiente seguro para milhares de estudantes'. A apresentação de um trabalho que pode ser considerado de menor valor na sociedade é acrescida de um argumento quantitativo, tanto da perspectiva dos colegas trabalhadores do sindicato, quanto dos estudantes, que são impactados pelo serviço de limpeza por eles prestado. Esse argumento destaca-se em função tanto da origem da imigrante, não europeia, como pela natureza do serviço prestado. Poderia ser visto, em certo sentido, como um modo de construção contradiscursiva que se contrapõe a um argumento que tende a focar os sujeitos que não pertencem à 
União Europeia como trabalhadores não qualificados (a partir de classificações de formação e de status socioeconômico).

Nos quatro exemplos da campanha, há uma concentração de imigrantes de origem europeia e que vivem na cidade de Londres. A origem de imigrantes da Europa é resultante tanto da história de imigração no Reino Unido ao longo dos últimos séculos, mas também da recente política de abertura das fronteiras da União Europeia para cidadãos europeus. Normalmente, esse argumento não tem sido utilizado para cidadãos de outras regióes do mundo. A cidade de Londres é considerada como uma cidade global pela quantidade de fluxos globais que ela recebe - econômicos, culturais, midiáticos, e também migratórios. Por essa razão, a cidade concentra o maior número de imigrantes (37\%) no país, seguida pela região de South East $(13 \%)^{45}$. Apesar da concentração maior de europeus nos posts do Twitter do que nos posters criados pela ONG, surgem traços raciais e étnicos menos homogêneos, como no caso do jovem negro e da mulher colombiana. Por outro lado, as dimensões de "participação" e de "contribuição" específica dos imigrantes à sociedade britânica está igualmente presente em todos os exemplos de posters compartilhados na internet. Em nenhum dos casos, contudo, aparece alguma menção às dificuldades de inserção, pertencimento, ou aos enfrentamentos com discriminações e racismos.

A partir da análise desenvolvida, evidenciamos que a campanha de comunicação de anti-xenofobia, denominada "I'm an Immigrant", posiciona-se como um contra-discurso, em torno da atual conjuntura migratória do Reino Unido, na medida em que instaura espaços de singularização e visibilidade das experiências dos migrantes visando o enfrentamento de discursos xenofóbicos de setores governamentais e da opinião pública pautados na generalização, quantificação e responsabilização dos imigrantes pelos problemas econômicos e sociais do país. Além disso, a campanha opera também para o questionamento das políticas migratórias do governo britânico que tem se concentrado principalmente numa perspectiva quantitativa, que busca estabelecer tanto números de imigrantes que podem ser recebidos, quanto valores mínimos de salários para a permanência dos imigrantes no país.

No entanto, aspectos discursivos que resultam da análise dos posters da campanha sugerem que a inserção no mundo do trabalho e a contribuição econômica dos imigrantes é a representação dominante que emerge como estratégia discursiva para fazer frente à xenofobia frente à imigração no Reino Unido. Tanto nos posters afixados em espaços públicos como naqueles produzidos por usuários na internet parecem convergir para um apagamento de outras dimensões que configuram as identidades imigrantes e que extrapolam

\footnotetext{
${ }^{45}$ Dados de 2014 do Observatório de Migração do Reino Unido, disponíveis em: <http://www. migrationobservatory.ox.ac.uk/briefings/migrants-uk-overview $>$.
} 
sua inserção no mundo do trabalho, como, por exemplo, as práticas culturais e religiosas e as dificuldades enfrentadas em seus processos de inserção na sociedade britânica, inclusive no mundo do trabalho.

Em termos estéticos, a campanha, tanto na rua como na internet, parece evidenciar, através das imagens de imigrantes que foram escolhidas, a opção por um padrão ocidental, europeu e branco, em que mesmo aqueles sujeitos de nacionalidades e origens étnicas não ocidentais e europeias exibem traços que parecem se aproximar desse padrão dominante. A ausência de outras marcas ou referentes culturais que possivelmente façam parte do universo cultural dos imigrantes visibilizados pela campanha (vestimentas, símbolos religiosos), etc., contribuem também para a composição desse tipo de padrão dominante, sugerindo, ainda, uma perspectiva assimilacionista que perpassa a campanha.

\section{Considerações finais}

Podemos considerar, a partir da análise desenvolvida nesse artigo, que a campanha "I am an Immigrant" parece assumir um viés economicista, associando imigração a trabalho e negando outras dimensões identitárias da vida dos imigrantes. Da mesma forma que as críticas aos fluxos de imigração concentram-se em questões econômicas, como a relacionada à competição entre nacionais e imigrantes no mercado de trabalho e aos custos sociais que os imigrantes representam para o governo, o texto da campanha busca, como contradiscurso, responder a esses elementos. Primeiramente desmistificando que os imigrantes somente teriam trabalhos precários, aspecto que não é enfaticamente discutido na campanha, e que é, muitas vezes, resultante das próprias políticas de imigração do país. Além disso, mostrando que o imigrante busca, por meio do trabalho e da sua trajetória, pertencer ao país onde vive atualmente, e, portanto, que ele traz contribuição para essa sociedade (não somente custos). Esses são aspectos relevantes em relação ao debate sobre cidadania das migrações transnacionais, na medida em que apontam para a necessidade de reconhecimento de direitos desses sujeitos pelas políticas do país, mas também para sentimento de pertencimento à sociedade local, onde os imigrantes passarão a viver e a estabelecer suas práticas e relações sociais.

Refletindo em relação ao discurso nessa campanha e à questão da imigração no Reino Unido, verificamos a necessidade de criação de espaços de visibilidade e de voz para os sujeitos imigrantes, questionando a opinião pública que os responsabiliza por problemas da sociedade local, que são, na realidade, muito mais complexos e amplos do que a presença de uma população migrante no país. Nessa perspectiva, a campanha também é uma forma de questionar as políticas do governo britânico em relação aos imigrantes, pautadas principalmente por uma perspectiva quantitativa, que estabelece tanto o número de imigrantes que 
podem ser recebidos, quanto os valores mínimos de salários para a permanência dos imigrantes no país.

Nesse aspecto, torna-se relevante problematizar a escolha da campanha por enfatizar a contribuição dos imigrantes pelo viés do trabalho, pois em muitos casos há a precarização e a submissão de não nacionais a condições desumanas de trabalho, na medida em que nem todos conseguem um bom emprego que possibilite sua participação de modo mais igualitária na sociedade britânica. De alguma forma, tanto o discurso da campanha quanto o discurso da opinião pública e do governo reforçam uma forma de discriminação dos imigrantes, sugerindo que somente seriam aceitos aqueles que realizarem de fato contribuições econômicas ao país.

Na perspectiva estética da discussão sobre cosmopolitismo, encontramos a reprodução de imagens de quem seriam os cidadãos do mundo, nesse caso o modelo estético ocidental, branco, e principalmente europeu. Além disso, a própria inclusão de elementos do trabalho, como a identificação de profissões como o médico, o bombeiro, a atleta, ou o uso de roupas de trabalho (uniformes em geral, terno e gravata), também colabora para demarcar um modo prioritário de falar do sujeito migrante na sociedade britânica. Questões polêmicas, como os processos de inserção de imigrantes de determinadas origens ou nacionalidades não tão "desejadas" (como aquelas de nações majoritariamente praticantes de religiões muçulmanas), ou as possibilidades efetivas de acesso dos imigrantes a serviços sociais, não são apresentadas ou discutidas pela campanha.

Já na perspectiva ética do cosmopolitismo, a questão do pertencimento e do reconhecimento pode ser observada, na campanha, tanto no que se refere ao apagamento das diferenças via uma expectativa de assimilacionismo dos indivíduos imigrantes às culturas locais e nacionais, quanto no que diz respeito à contribuição efetiva, para a sociedade local, das trajetórias profissionais narradas nos posters.

Se, por um lado, a campanha busca dar visibilidade às particularidades culturais dos imigrantes, por outro lado, essas particularidades despontam via o apagamento, nos textos apresentados, de algumas diferenças na condição dos imigrantes representados. Há inclusive uma certa ênfase em uma perspectiva assimilacionista, como se esses sujeitos tivessem assimilado suas identidades ao país de destino, e que ajudam, contribuem e apoiam sua construção, sem nenhuma referência a distinções em relação à suas culturas e seus países de origem. Assim, a relação com a diferença não é apresentada, muito menos a menção a atos de xenofobia vivenciados por imigrantes. Paradoxalmente, a campanha, criada para dar visibilidade aos imigrantes e para diminuir os casos de ações xenófobas não combate essas questões especificamente, apagando-as da discussão. Como aponta a síntese de Sayad ${ }^{46}$, não é pela identidade imigrante que

46 SAYAD, op. cit. 
o sujeito deve ser definido ou por sua identidade cultural fixa, mas é fundamental a adoção de uma visão de alteridade, que inclui o Outro na relação entre suas duas realidades (a de origem e a de destino).

Como apresentado na pesquisa realizada pelo Migration Observatory de Oxford e mencionada nesse artigo, as atitudes de xenofobia se dirigem majoritariamente aos imigrantes de trabalhos precários, de baixo valor, ou refugiados. Essa questão também aparece nas decisões recentes do governo britânico sobre o valor mínimo de salário para permanência dos imigrantes, e nas barreiras criadas para entrada de refugiados no país. A campanha aqui analisada, criada para dar visibilidade aos imigrantes e para diminuir os casos de ações xenófobas, não combate essas questões especificamente, apagando-as da discussão.

Como resultado das votações que ocorreram no final de 2015 e no início de 2016, a regulamentação e a política britânicas em relação aos imigrantes tornaram-se ainda mais duras, tanto para a permanência de indivíduos no país (com exigência de recursos financeiros mínimos de 35 mil libras por ano para os imigrantes que não forem cidadãos europeus), quanto para a entrada de novos imigrantes (com foco no fechamento das fronteiras principalmente para os refugiados). Como resposta a essas decisões, destacamos primeiramente a reportagem feita pelo jornal britânico Independent ${ }^{47}$ em fevereiro de 2016, que entrevistou imigrantes que serão afetados pela decisão sobre o teto mínimo para permanência, mostrando suas identidades e suas histórias de vida, com proposta semelhante à própria campanha analisada nesse artigo. Outra forma de dar visibilidade, a partir de fluxos comunicacionais, à questão dos imigrantes, especificamente sobre os refugiados no campo em Calais (na fronteira entre a França e o Reino Unido), que não têm permissão para entrar em território britânico, foi a intervenção realizada em janeiro de 2016 pelo artista Banksy na embaixada francesa em Londres ${ }^{48}$. Essa obra tinha como imagem a menina personagem do romance Os miseráveis, de Victor Hugo, envolta em uma nuvem de gás, juntamente com um código para visualização de um vídeo feito no campo de refugiados onde, dentre outros, foi utilizado esse tipo de violência.

A visibilidade comunicacional das questões relacionadas às migrações é uma forma de problematizar o cosmopolitismo em suas diferentes possibilidades de experiência e de reposicionar a questão da alteridade na sociedade contemporânea. Nessa perspectiva, a campanha "I am an Immigrant" adotou um tipo de estratégia para combater o discurso de xenofobia presente na opinião pública britânica, assim como as políticas migratórias do governo. Com uma natureza um pouco distinta, mas também contra a xenofobia, foi lançada

\footnotetext{
${ }^{47}$ Reportagem disponível em: <http://www.independent.co.uk/news/uk/home-news/theresa-mayteachers-charity-workers-nhs-staff-scientists-kick-out-of-britain-stop35k-a6853891.html > .

${ }^{48}$ Ver referência no artigo disponível em: < http://www.theguardian.com/artanddesign/2016/jan/24/ banksy-uses-new-artwork-to-criticise-use-of-teargas-in-calais-refugee-camp>.
} 
em outubro de 2015 uma campanha pelo governo brasileiro denominada \#Eutambemsouimigrante ${ }^{49}$, com foco na história e na descendência de imigrantes no país. Com elementos das duas campanhas (a britânica e a brasileira), foi lançada em fevereiro de 2016 pela ONG global Refunite ${ }^{50}$ (em parceria com uma agência brasileira) a proposta \#IMMIGRANT ${ }^{51}$, que resgata tanto a apresentação da identidade do imigrante, mas também remete à história de família relacionada à migração. A exemplo da campanha aqui estudada, essas iniciativas surgem, portanto, como uma resposta e como uma alternativa para discursos presentes na opinião pública e na mídia - próximos a uma visão nacionalista e não cosmopolita - sobre as experiências migratórias contemporâneas.

\section{Bibliografia}

BAUMAN, Zygmunt. Modernity and Ambivalence. In FEATHERSTONE, Mike (ed.). Global Culture. London: Sage, 1990.

BECK, Ulrich. Qu'est-ce que le cosmopolitisme? Paris: Aubier, 2006.

BILBENY, Norbert. La identidad cosmopolita. Barcelona: Kairós, 2007.

CICCHELLI, Vincenzo; OCTOBRE, Sylvie. A cosmopolitan perspective of globalization: cultural and aesthetic consumption among young people. Studies of Changing Societies: comparative and interdisciplinary focus, v. 3, n. 7, 2013.

CICCHELLI, Vincenzo; OCTOBRE, Sylvie. Sur le cosmopolitisme esthétique chez les jeunes. Le Débat, n. 183, 2015/1. Paris: Gallimard, 2015.

CICCHELLI, Vincenzo; OCTOBRE, Sylvie; RIEGEL, Viviane. Reflections on global culture and aesthetic cosmopolitanism. Global Studies Journal, v. 9, n. 1, 2016, p. 55-70.

CORTINA, Adela. Por una ética del consumo: la ciudadanía del consumidor en un mundo global. Madri, Taurus: 2002.

CORTINA, Adela. Ética sem moral. São Paulo: Martins Fontes, 2010.

DELANTY, Gerard. The cosmopolitan imagination: critical cosmopolitanism and social theory. British Journal of Sociology, v. 57, n. 1, 2006, p. 25-47.

FAIRCLOUGH, Norman. Discurso e mudança social. Brasília: Ed.UNB, 2001.

HALL, Stuart. Cultural Identity and Diaspora. In WOODWARD, Kathryn (ed.). Identity and Difference. London: Sage, 1997.

HANNERZ, Ulf. Cosmopolitans and locals in world culture. In FEATHERSTONE, Mike (ed.). Global culture. London: Sage, 1990.

MEZZADRA, Sandro. Derecho de fuga: migraciones, ciudadanía y globalización. Madrid: Traficantes de Sueños, 2005.

SASSATELLI, Monica. Festivals, museums, exhibitions: aesthetic cosmopolitanism in the cultural public sphere. In DELANTY, Gerard (ed.). Handbook of cosmopolitan studies. London: Routledge, 2012, p. 233-244.

\footnotetext{
${ }^{49}$ Disponível no site: <http://www.eutambemsouimigrante.com.br>.

${ }^{50}$ Cf. $<$ https://refunite.org $>$.

${ }^{51}$ Disponível no site: $<$ http://immigrant.im/>.
} 
SAYAD, Abdelmalek. L'immigration ou les paradoxes de l'altérité. Paris: Editions Raisons d'Agir, 2006.

SKRBIS, Zlatko; WOODWARD, lan. Cosmopolitanism: uses of the idea. London: Sage, 2013.

URRY, John. Consuming Places. London: Routledge, 1995.

VAN DIJK, Teun A. (comp.). El discurso como interacción social. Barcelona: Gedisa, 2005.

\section{Abstract}

"I'm an Immigrant": cosmopolitanism, alterity and communicational flows in an anti-xenophobia campaign in the UK

This article aims to reflect on the relationship between communication, cosmopolitanism and alterity in migration processes, based on the critical discourse analysis of an anti-xenophobia advertising campaign called "I'm an Immigrant", held in 2015 in the UK. From a conceptual discussion on notions of cosmopolitanism, identity, alterity, in its connections with representations and citizenship practices of transnational migrations, we analyzed the discourses of the campaign pieces' texts that have been placed in urban areas of the city of London and in digital spaces on the internet. The analysis showed that the campaign contributes to give visibility to migrants, singularizing their trajectories. However, this singularity is built on the one hand, on the emphasis in an economistic dimension that associates immigration to work, without exposing its contradictions, and, on the other hand, based on a western, white and secular model, which operates for the erasure of differences that constitute UK's migratory cultures.

Keywords: transnational migrations, cosmopolitanism, alterity, communicational flows, United Kingdom.

Recebido para publicação em 10.02.2016

Aceito para publicação em 21.03.2016

Received for publication in February 10

Accepted for publication in March 215t, 2016

ISSN impresso 1980-8585

ISSN eletrônico 2237-9843

http://dx.doi.org/10.1590/1980-85852503880004603 


\section{ERRATA}

No artigo, "I'm an immigrant": cosmopolitismo, alteridade e fluxos comunicacionais em uma campanha anti-xenofobia no Reino Unido, com número de DOI: 10.1590/1980-85852503880004603, publicado na Revista REMHU, Revista Interdisciplinar da Mobilidade Humana, ano XXIV, número 46, na página 23 , nota de rodapé 1 ,

Onde se lia:

Professora Titular do Programa de Pós-Graduação em Comunicação e Práticas de Consumo da ESPM-SP. Bolsista CAPES/Prosup. São Paulo, SP, Brasil.

Leia-se:

Professora Titular do Programa de Pós-Graduação em Comunicação e Práticas de Consumo da ESPM-SP. Pesquisadora do CNPq. São Paulo, SP, Brasil. 